\title{
Duas espécies novas de Centris (Heterocentris) Cockerell, da região amazônica e do Brasil Central (Hymenoptera, Apoidea) '
}

\author{
Jesus Santiago Moure ${ }^{2}$ \\ 1 Contribuição número 1425 do Departamento de Zoologia, Universidade Federal do Paraná. \\ 2 Departamento de Zoologia, Universidade Federal do Paraná. Caixa Postal 19020, 81531-980 Curitiba, Paraná, Brasil. \\ Pesquisador do CNPq. E-mail: jsmoure@bol.com.br
}

\begin{abstract}
Two new species of Centris (Heterocentris) Cockerell, from amazon region and Central Brazil (Hymenoptera, Apoidea). Two species of Centris (Heterocentris) are described as new: Centris (Heterocentris) adunca from Venezuela (Amazonia) and Brazil (Acre) and Centris (Heterocentris) flavicans from Central Brazil (Goiás). The main character of $C$. (H.) adunca sp. nov. is a crooked tubercle implanted on the basis of clypeus with the apex truncate and slightly bifurcated and a unarmed labrum, and of $C$. (H.) flavicans sp. nov. the hairs on scutum and scutellum completely yellow. Centris labrosa Friese, 1899 is a new synonym for Centris terminata Smith, 1874.
\end{abstract}

KEY WORDS. Centris(Heterocentris) adunca, Centris (Heterocentris) flavicans, Neotropical taxonomy.

Dá-se a conhecer uma espécie notável entre as Centris Fabricius, 1804, pela presença de uma saliência em forma de chifre, curvada para baixo apicalmente, com a ponta levemente bilobada, saindo do terço superior do clípeo. Neste gênero há mais uma espécie no Caribe, descrita originalmente de Cuba como Centris ? cornuta Cresson, 1865, com uma saliência em chifre voltada para baixo em curva suave, porém o ápice progressivamente aguçado e a base muito larga ocupando toda a parte média do clípeo, este curtíssimo, quatro vezes mais largo que longo.

CREsSON (1865), termina seus longos comentários sobre C. cornuta com seguintes dizeres, em grande parte aplicáveis à espécie nova aqui descrita: "This singular species is remarkable for the curiously constructed head, which differs from that of any other Hymenopterous insects known to me. The structure of the antennae and legs, and the neuration of the wings, coincide with that of Centris, but the shape of the head, and of the clypeus, labrum and mandibles, is so very different, that the species will doubtless form a new genus, for which I would propose the name of Gundlachia, which may be more fully determined when more specimens have been discovered, and when the parts of the mouth can be examined". Quando estudei os tipos de Cresson em Philadelphia (1957), esta espécie já não estava lá.

Michener (1997), informa que o nome proposto por Cresson (Gundlachia) está preocupado por PFeIfFer (1850) (Mollusca), e que esta espécie pertence a C. (Heterocentris) Cockerell, 1899, não sendo necessário criar novo subgênero. Esse mesmo nome foi ainda utilizado por HERRICH-SCHÄFFER (1866) (Lepidoptera).

Em C. (Heterocentris) os dois dentes basais da mandíbula das fêmeas são pouco ou nada separados no ápice, porém bem mais claramente bidentado nos machos, como se vê em C. (H.) flavicans sp. nov. (Fig. 5). O labro é bastante variado: às vezes claramente bidentado no ápice como em C. bicornuta Mocsary, 1899 (Fig. 6), lembrando um pouco o de C. difformis (Fig. 4); truncado apicalmente, plano até a ponta e sem qualquer tipo de armação, apenas um pouco engrossado e arredondado nos cantos como em C. adunca sp. nov. (Figs 1-2); com um extraordinário espinho cônico alargado para a base, um pouco maior que o "corno" do clípeo, como em C. cornuta (Fig. 3).

O clipeo em C. (H.) cornuta é muito curto, largo e estreito, e a base do "corno" ocupa quase toda parte média; as mandíbulas são longas e estreitas, fortemente bidentadas no ápice, o dente basal simples e pequeno. Em C. (H.) adunca sp. nov. o clípeo é de comprimento normal, com o corno implantado no seu terço basal; as mandíbulas de comprimento normal, como em outras C. (Heterocentris), alargadas para a base e o dente basal simples, agudo, bastante saliente. Em C.(H.) bicornuta, é notável a presença dos "chifres", um a cada lado da margem inferior do clípeo.

Outra diferença marcante está na largura da gena, com relação à largura do olho em vista lateral, em C. (H.) cornuta da mesma largura (30:30) e em C. (H.) adunca sp. nov. notavelmente mais estreita (30:20). O abdome tem um tom vermelho muito escuro e a pilosidade no disco do mesoscuto preta em $C$. (H.) cornuta, enquanto que em C. (H.) adunca sp. nov. o abdome é pálido-avermelhado e a pilosidade no disco do mesoscuto toda pálida, igual ao restante.

Michener (2000), coloca C. (Hemisiella) Moure, 1945 na sinonímia de $C$. (Heterocentris) Cockerell, 1899. Estes dois subgêneros são bem diferentes e muito fáceis de separar. A placa pigi- 
dial superior da fêmea de $C$. (Heterocentris) é largamente truncada, com os cantos um pouco arredondados, enquanto de $C$. (Hemisiella) é completa e aguda. O desenho do clípeo da fêmea de C. (Heterocentris) está formado por dois triângulos afastados e com as pontas viradas para cima [para a base do clípeo], mais ou menos deformados (Figs 2 e 6), às vezes soldados entre si, chegando a formar uma faixa transversal como na espécie tipo do gênero (Fig. 4); nos machos parece um chapéu ou cartola (Fig. 5). Em C. (Hemisiella), a fêmea também tem duas manchas clipeais amarelas, triagulares, os triângulos inclinados para o meio, deixando uma grande mancha escura triangular entre elas com a base no bordo inferior; nos machos uma faixa levemente arqueada para cima, às vezes com fina separação média. Outro caráter importante para a manutenção desse subgênero, ressaltado por RoIg Alsina (2000), é a diferença da pilosidade ventral do tórax, onde os pêlos são simples e com a ponta recurvada.

Em Londres, vi uma fêmea de C. (H.) cornuta, do Haití (Grande Anse, P.R. Uhler). A diagnose de Cresson é absolutamente clara, e não sei como esse exemplar foi colocado entre os de C. (H.) difformis Smith, 1854, espécie tipo do subgênero (Fig. 4), no The Natural History Museum, Londres.

A seguir é dada a descrição de Centris (Heterocentris) adunca sp. nov. e Centris (Heterocentris) flavicans sp. nov.

A sigla "dp" significa quantos diâmetros de ponto tem o intervalo entre os mesmos; " $\mathrm{T}$ " tergo e " $\mathrm{E}$ " esterno. Os valores entre parênteses são dados em centésimos de milímetro, caso não haja indicação expressa em contrário.

\section{Centris (Heterocentris) adunca sp. nov. Figs $1-2$}

Fêmea. Comprimento aproximado do corpo $12,5 \mathrm{~mm}$ e da asa 8,33 mm; largura da cabeça $4,25 \mathrm{~mm}$ e do T2 4,1 $\mathrm{mm}$.

Cabeça preta com numerosos desenhos amarelos: quase todo o clípeo, com exceção da faixa mediana (longitudinalmente), da projeção adunca, do bordo inferior, das margens laterais, e da face superior e lateral (essa parte superior em arco até as fóveas tentoriais); o labro com uma mancha grande discal em V, igualmente preta, e uma fina estria nas margens laterais; no clípeo finamente as margens e o bordo apical; nos $2 / 3$ basais das mandíbulas uma grande mancha amarela discal e com as margens pretas. Todo o tórax e propódeo pretos e quase por inteiro as pernas anteriores com os tarsos mais para o ferrugíneo; desta última cor grande parte dos fêmures médios e posteriores, quase por inteiro as tíbias e basitarsos posteriores e quase todo o abdome menos a maior parte basal de T1.

A pilosidade em grande parte amarelenta, passando a mais esbranquiçada na fronte e lados da face, do labro e das genas; preta no vértice; amarela na parte dorsal do tórax e mais esbranquiçada nos lados, nestes inferiormente mais rala; esbranquiçada atrás nos fêmures médios e posteriores; na escopa e basitarsos amarelados. A pilosidade nos três primeiros tergos e base do quarto muito fina, preta.

A pontuação como em outras Heterocentris. As partes descobertas da face e labro relativamente lisas; no mesoscuto a pontuação mais evidente, os intervalos um pouco maiores que um dp; os pontos para o disco um pouco maiores e os intervalos mais lisos; o metanoto e disco da área basal quase inteiramente lisos e brilhantes com poucos pontos esparsos mais para baixo e para os lados; nos tergos mais fina.
Clípeo mais saliente em cima (face superior)e no meio da base, com uma forte projeção em espinho adunco de ápice truncado e levemente biemarginado. O labro muito desenvolvido (180 de comprimento, por 180 de largura na base e 140 no ápice), largamente truncado, arredondado-engrossado no ápice e aos lados, com curta emarginação média em arco muito aberto e os cantos laterais levemente projetados para cima. As mandíbulas com forte curva nos dois quintos apicais e com um forte dente no lado interno do terço basal; artículos do flagelo 80:18:20:20:20 diâmetro 20. O escapo curto (70) e grosso (37); o pedicelo e flagelo juntos 320 .

Holótipo fêmea da Venezuela, nascente do Rio Orinoco, "Culebra" (Amazonia), 26-01-1992, Dieter Wittmann leg. Um parátipo fêmea, da Reserva Catuaba, Senador Guiomard, Acre, Brasil $\left(10^{\circ} 04^{\prime} \mathrm{S}\right.$ e $67^{\circ} 36^{\prime} \mathrm{W}$ [próxima de Rio Branco]), 18-VIII2002, Elder F. Morato leg. Holótipo e parátipo depositados na Coleção de Entomologia Pe. J.S. Moure, Departamento de Zoologia da Universidade Federal do Paraná (DZUP).

Etimologia. O nome desta espécie refere-se ao corno clipeal, fortemente curvado para baixo, um pouco alargado para a ponta, com o ápice truncado e levemente biemarginado.

Comentários. Tive por longos anos (desde 1940), na minha coleção, um exemplar desta nova espécie, que me foi doado pelo Dr. Samuel B. Pessôa, do Departamento de Parasitologia, Faculdade de Medicina de São Paulo, coletado por seu laboratorista, Worontzoff, numa de suas viagens à Amazônia (Parintins e Maués, para coleta de Culicidae para as aulas práticas). O exemplar foi coletado em Maués, altitude de $25 \mathrm{~m}$, nas margens do rio desse mesmo nome, mais ao sudoeste de Parintins, no Estado do Amazonas, quase a meio caminho entre o Acre e a Venezuela, de onde descrevo a espécie. Pelo trabalho de Friese (1900), tinha-o determinado erradamente como $C$. (H.) cornuta Cresson, 1865. Infelizmente, o referido exemplar foi perdido, não estando mais na Coleção de Entomologia Pe. J.S. Moure, Departamento de Zoologia, Universidade Federal do Paraná (DZUP).

\section{Centris (Heterocentris) flavicans sp. nov. Fig. 5}

Macho. Comprimento total aproximado $=12,55 \mathrm{~mm}$, da asa 9,20 mm; largura da cabeça 4,00 $\mathrm{mm}$ e de T2 4,15 $\mathrm{mm}$.

A cabeça preta, com o clípeo quase inteiramente amarelo, em forma de cartola (Fig. 5) deixando estreita faixa preta acompanhando a sutura epistomal até as fóveas tentoriais, passando a mais estreita abaixo das fóveas; uma pequena mancha próxima ao ápice do escapo; as genas pretas; o labro amarelo com o bordo finamente marginado de um pardo desbotado; as mandíbulas com grande mancha amarela marginada de preto, mais largamente em cima e nos dentes; pequena mancha amarela na base das tíbias anteriores. O tórax preto; as pernas pardo-ferrugíneas, os fêmures posteriores bastante escuros, um pouco menos para a extremidade apical; a margem anterior dos basitarsos posteriores um pouco pardacenta. O abdome amarelo-ferrugíneo, com a margem do segmento basal bastante escura, as margens dos seguintes mais fracamente.

A pilosidade da cabeça pálida, quase branca nas genas, alguns pêlos escuros junto aos ocelos e aos escapos lateralmente. Amarelenta no mesoscuto, incluindo o ápice dos pêlos, mais pálida no escutelo, pleuras e pernas, um pouco pardacenta nos tarsos 2-4. Mais pálida no propódeo; pálida no primeiro tergo; 

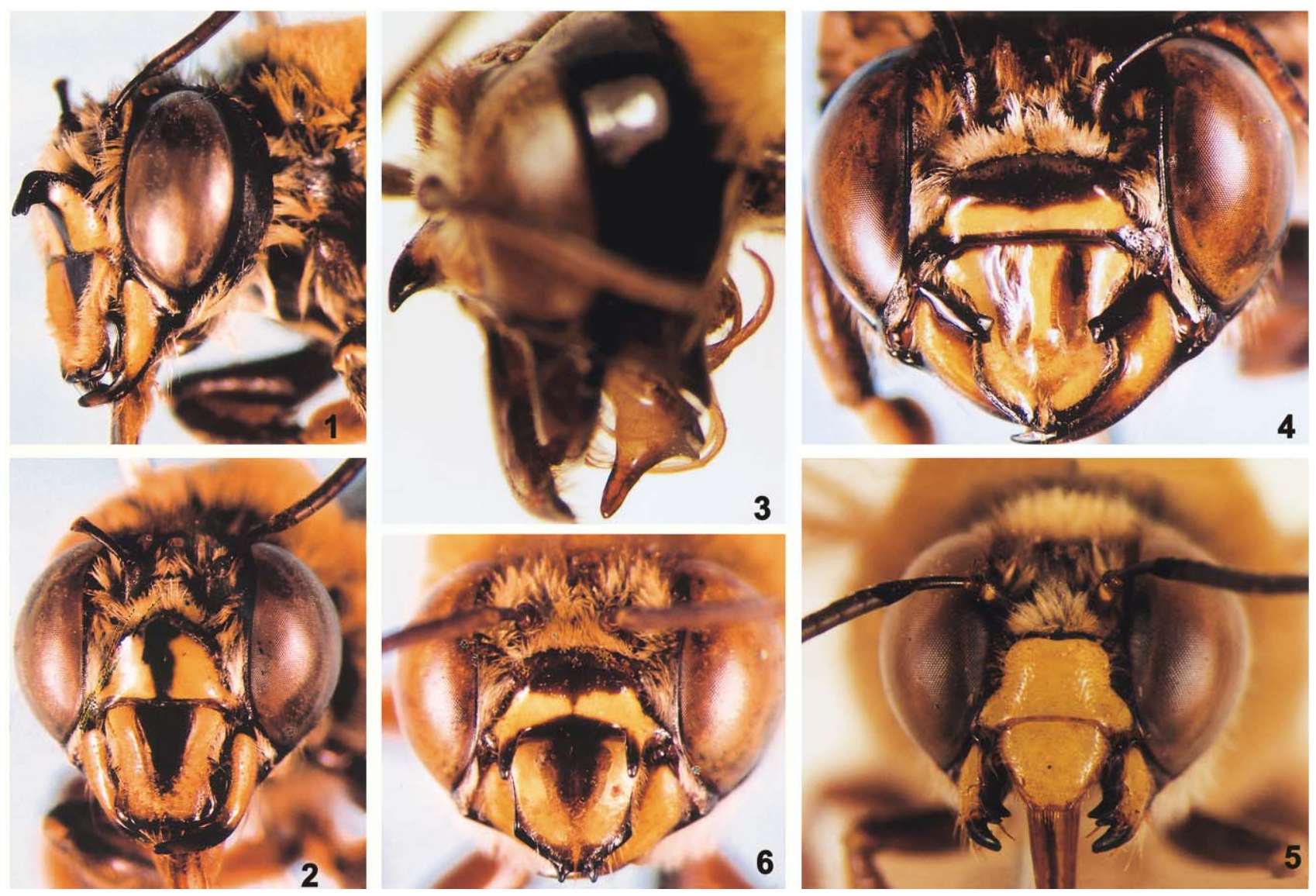

Figuras 1-6.(1-2) Centris (Heterocentris) adunca sp. nov., cabeça do holótipo: (1) vista lateral, (2) vista frontal; (3) Centris (Heterocentris) cornuta, fêmea, vista lateral da cabeça; (4) Centris (Heterocentris) difformis, fêmea, vista frontal da cabeça; (5) Centris (Heterocentris) flavicans sp. nov., vista frontal da cabeça do holótipo; (6) Centris (Heterocentris) bicornuta, fêmea, vista frontal da cabeça.

preta nas extremidades apicais de T1, inteiramente em T2-4 e base do T5, porém na metade apical do quinto pálida bem como T6-7 por inteiro. Pálida em todos os esternos.

Pontuação moderada e em grande parte oculta pela pilosidade; muito esparsa no vértice, quase nula ao longo do meio do clípeo alargando-se essa área para o ápice e no meio basal do labro; no propódeo mais esparsa que no mesoscuto, escutelo e pleuras, chegando de 3-5 dp na face posterior. Nos tergos relativamente densa na base e ficando um pouco mais esparsa atrás; nas depressões marginais quase nula na metade posterior.

A cabeça mais larga que longa (400:248), os olhos mais longos que largos (275:160), o clípeo bem mais largo que longo (184:96); a distância interocelar (54:15) e o diâmetro do ocelo médio 15, igual à distância ocelorbital. As mandíbulas tridentadas com o dente apical mais longo que os dois basais; estes unidos entre si e igualmente agudos; o labro um pouco mais curto que sua largura basal (100:125); com os lados convergindo para o ápice, este truncado em linha reta (38); o escapo relativamente engrossado para o ápice (30:60); o flagelo (368) aproxi- madamente seis vezes mais longo que o escapo. O basitarso posterior (148) mais longo que os três seguintes juntos e com um espinho bastante robusto (60) soldado ao bordo posterior.

O Holótipo (macho), foi coletado em Goiás (atual Goiás Velho), antiga capital do Estado de Goiás, em 22/VII/1977, pelo Dr. Antony Raw, em flores de Physocalyma scaberrimum (Bignoniacea). Holótipo depositado na Coleção de Entomologia Pe. J.S. Moure, Departamento de Zoologia da Universidade Federal do Paraná (DZUP).

Etimologia. O nome desta espécie refere-se à cor amarelada dos pêlos.

Comentários. Bastante parecida pelo colorido e pilosidade com C. (Hemisiella) trigonoides, tendo até um espinho no bordo posterior dos basitarsos posteriores. O desenho amarelo do clípeo em C. (Heterocentris) flavicans sp. nov. semelhante a uma cartola (Fig. 5), facilmente separa as duas espécies. Entre as Heterocentris, a que mais se assemelha é $C$. (H.) terminata Smith, 1874 ( = C. labrosa Friese, 1899, syn. nov.), separandose facilmente pelo revestimento piloso do mesoscuto, em $C$. (H.) terminata com a ponta dos pêlos preta. SMITH (1874) não 
chama a atenção para esse particular na sua descrição, evidente no tipo conservado no The Natural History Museum, Londres.

\section{AGRADECIMENTOS}

À doutoranda Favízia Freitas de Oliveira, pelas fotografias e pela revisão do texto.

\section{REFERÊNCIAS BIBLIOGRÁFICAS}

CRESSON, E.T. 1865. On the Hymenoptera of Cuba. Proceedings of the Entomological Society of Philadelphia 4:1-200.

FrIESE, H. 1899. Neue Arten der Bienengattungen Epicharis Klug und Centris Fabr. Térmeszetrajzi Füzetek 23:39-48.

. 1900. Monographie der Bienengattung Centris (s. lat.). Annalen der K. K. Naturhistorischen Hofmuseum, Wien, 15: 237-350.

Herrich-Schäffer, G.A.W. 1866. Schmetterlinge aus Cuba.
Correspondenz-Blatt des zoologisch-mineralogischen Vereines in Regensburg, 20: 103-109.

Michener, C.D. 1997. Genus-Group Names of Bees and Supplemental Family-Group Names. Scientific Papers of the Natural History Museum of the University of Kansas 1: 1-81.

Michener, C. D., 2000. The Bees of the World. Baltimore, Johns Hopkins University Press, XIV+913p.

Pfeiffer,L., 1849 [1850]. Monographia Helicearum viventium, in Neue Moluskengattungen. Zeitschrift für Malakozoologie, 6:97-105.

Roig Alsina, A. 2000. Claves para las especies argentinas de Centris (Hymenoptera, Apidae), com descripción de nuevas especies y notas sobre distribución. Revista do Museu Argentino de Ciencias Naturales, n.s., Buenos Aires, 2 (2): 171-193.

Sмiтн, 1874. A revision of the genus Epicharis, Centris, Eulaema and Euglossa belonging to the family Apidae, Section Scopulipedes. Annals and Magazine of Natural History, London, 13 (4): 357-373.

Recebido em 13.I.2003; aceito em 22.V.2003.

Revista Brasileira de Zoologia 20 (2): 265-268, junho 2003 